\title{
GAMBARAN PENGETAHUAN IBU HAMIL TRIMESTER I TENTANG HIPEREMESIS GRAVIDARUM \\ (di Wilayah Puskesmas Tiron Kecamatan Banyakan Kabupaten Kediri)
}

Aida Ratna Wijayanti ${ }^{1}$, Clara Rizkiawanti Larasasti Suwito ${ }^{2}$

${ }^{1,2}$ Akademi Kebidanan Dharma Husada Kediri Jawa Timur

\begin{abstract}
Abstrak
Hiperemesis Gravidarum adalah mual muntah yang berlebihan sehingga menimbulkan gangguan aktivitas sehari-hari dan bahkan sampai membahayakan hidup ibu hamil. Disamping itu juga hiperemesis gravidarum yaitu mual muntah yang berat sehingga dapat menyebabkan pekerjaan sehari-hari menjadi terganggu dan keadaan umum ibu menjadi buruk. Tujuan penelitian ini adalah untuk mengetahui gambaran pengetahuan ibu hamil trimester I tentang hiperemesis gravidarum di Wilayah Puskesmas Tiron Kecamatan Banyakan Kabupaten Kediri.

Desain penelitian ini menggunakan desain penelitian deskriptif dengan pendekatan Cross Sectional. Penelitian ini dilakukan tanggal 1-10 agustus 2017. Semua ibu hamil trimester I di Wilayah Puskesmas Tiron Kecamatan Banyakan Kabupaten Kediri dengan jumlah populasi 35 responden, dengan teknik Accidental Sampling diperoleh sampel sejumlah 30 responden. Variabel pada penelitian ini adalah variable mandiri (Tunggal) yaitu Gambaran pengetahuan Iu hamil trimester I tentang hiperemesis gravidarum. Instrumen penelitian menggunakan kuesioner yang sudah diuji validitas dan reliabilitas. Pengolahan data meliputi Editing, Coding, Skoring, Tabulating. Dan analisa data meggunakan Prosentase.

Hasil penelitian menunjukan dari 30 responden yaitu ibu hamil trimester I yang mengalami hiperemesis gravidarum sebagian besar berpengetahuan cukup yaitu sejumlah 17 responden $(56,6 \%)$, Baik 3 responden (10\%) dan Kurang 10 responden (33\%). Kemudian untuk ibu hamil trimester I yang memiliki pengetahuan Baik tentang pengertian hiperemesis gravidarum sejumlah 13 responden $(43,3 \%)$, pengetahuan cukup tentang penyebab hiperemesis gravidarum sejumlah 16 responden $(53,3 \%)$. Pengetahuan Cukup tentang diagnosis hiperemesis gravidarum sejumlah 17 responden $(56,6 \%)$. Pengetahuan Kurang tentang Pencegahan hiperemesis gravidarum sejumlah 16 responden $(53,3 \%)$.

Berdasarkan hasil penelitian tersebut disimpulkan bahwa pengetahuan ibu hamil trimester I di Wilayah Puskesmas Tiron Kecamatan Banyakan Kabupaten Kediri mempunyai pengetahuan cukup 17 responden $(56,6 \%)$. Disarankan pada tenaga kesehatan untuk memperbanyak penyuluhan agar pengetahuan ibu hamil khususnya untuk trimester I memiliki wawasan luas tentang hiperemesis gravidarum.
\end{abstract}

Kata kunci : Pengetahuan, Hamil, Hiperemesis Gravidarum

131 | Jurnal Kebidanan Dharma Husada Vol. 6, No. 2 Oktober 2017 


\section{Pendahuluan}

Kehamilan merupakan suatu proses fisiologis yang terjadi pada wanita yang dimulai dari konsepsi sampai lahirnya janin, lamanya kehamilan normal yaitu 280 hari (40 minggu atau 9 bulan 7 hari) dihitung dari pertama haid terakhir. Kehamilan terbagi dalam 3 trimester, dimana trimester kesatu berlangsung dalam 12 minggu, trimester kedua 15 minggu(minggu ke13 hingga ke-27) (Sarwono,2008:213).

Permasalahan pada trimester pertama misalnya yaitu perasaan mual muntah akibat kadar estrogen meningkat mual muntah terus menerus dapat menyebabkan dehidrasi. Muntah yang lebih dari sepuluh kali sehari atau atau mual terus menerus yang terjadi selama 20 minggu terakhir kehamilan ini akan berlanjut menjadi Hiperemesis gravidarum sehingga tubuh ibu menjadi lemah, muka pucat, dan frekuensi buang air kecil menurun drastic (Widya, 2015). Penyebab hiperemesis gravidarum belum diketahui secara pasti. Perubahan-perubahan anatonik yang terjadi pada otak, jantung, hati dan susunan syaraf, disebabkan oleh kekurangan vitamin serta zat-zat lain akibat kelemahan tubuh karena tidak makan dan minum. Faktor lain yang ditemukan oleh beberapa sebagai berikut:Faktor psikologi memegang peranan yang penting pada penyakit ini , rumah tangga yang retak,kehilangan pekerjaan, takut akan kehamilan dan persalinan, kehilangan pekerjaan , takut terhadap tanggung jawab sebagai ibu, dapat menyebabkan konflik mental yang dapat memperberat mual dan muntah sebabai ekspresi tidak sadar terhadap keengganan menjadi hamil atau sebagai pelarian kesukaran hidup. Kurangnya penerimaan terhadap kehamilan dinilai memicu perasaan mual dan muntah ini. Pada waktu hamil muda kehamilan dinilai tidak diharapkan apakah karena kegagalan kontrasepsi ataupun karena hubungan diluar nikah. Hal ini bisa memicu ibu terhadap kehamilan tersebut (Yulianti, 2013:118).

Mual muntah berlebih yaitu lebih dari 10 kali dalam 24 jam disertai penurunan nafsu makan yang biasa disebut dengan Hiperemesis gravidarum. Keadaan seperti ini dapat mengganggu aktivitas ibu sehari-hari. Terdapat sebanyak 8,6juta ibu hamil menjadi kehilangan jam kerjanya karena masalah ini.(Anggasari, 2016)

Komplikasi hiperemesis gravidarum terdapat pada sekitar $60-80 \%$ primigravida dan pada $40-60 \%$ multigravida . Gejala ini menjadi lebih berat pada 1 dari 1.000 kehamilan, namun kejadian ini akan berakibat fatal jika tidak segera ditangani (Anggasari, 2016). Menurut World Health Organization (WHO) jumlah kejadian hiperemesis gravidarum mencapai $12,5 \%$ dari jumlah seluruh kehamilan di dunia. Mual dan muntah dapat mengganggu dan membuat ketidakseimbangan cairan pada jaringan ginjal dan hati menjadi nekrosis (WHO, 2013). Berdasarkan hasil penelitian di Indonesia diperoleh data ibu dengan hiperemesis gravidarum mencapai $14,8 \%$ dari seluruh kehamilan. Keluhan mual dan muntah terjadi pada $60-80 \%$ primigravida dan $40-60 \%$ multigravida. Satu diantara seribu kehamilan gejala-gejala ini menjadi lebih berat (Depkes RI, 2013). Data yang akurat tentang angka kejadian hiperemesis gravidarum tidak banyak dipublikasikan. Sekitar $60-80 \%$ multigravida mengalami mual muntah, namun gejala ini terjadi lebih berat hanya pada $1 \mathrm{di}$ antara 1.000 kehamilan. Angka kejadian hiperemesis gravidarum di Indonesia tahun 2015 adalah 1,5$3 \%$ dari wanita hamil, sedangkan kejadian hiperemesis gravidarum di Propinsi Jawa Timur pada Trimester1-2 atau pada cakupan K1-K2 mencapai $10-15 \%$ dari jumlah ibu hamil yang ada yaitu sebanyak 182.815 orang pada tahun 2015 (Depkes, 2017).

Berdasarkan studi pendahuluan dari wilayah puskesmas Tiron pada tanggal 19 april 2017 dari $10 \mathrm{ibu}$ hamil yang dijadikan responden. 4 dari $10 \mathrm{ibu}$ hamil mengalami gangguan aktivitas sehari hari seperti mual muntah secara terus menerus dan tidak memeriksakan ke bidan. Berdasarkan uraian di atas tujuan dari penelitian ini adalah untuk mengetahui gambaran Pengetahuan Ibu 
Hamil Trimester I Tentang Hiperemesis Gravidarum di Wilayah Puskesmas Tiron Desa Banyakan Kecamatan Banyakan Kabupaten Kediri.

\section{Metode}

Penelitian ini menggunakan desain deskriptif (descriptiv reseach) dengan pendekatan Cross
Sectional. Popuasi dalam penelitian ini adalah seluruh Ibu hamil Trimester I di Wilayah Puskesmas Tiron Kecamatan Banyakan Kabupaten Kediri berjumlah 35 Responden.

Sample dalam penelitian ini adalah $30 \mathrm{ibu}$ hamil Trimester I di Wilayah Puskesmas Tiron Kecamatan Banyakan Kabupaten Kediri

Hasil

Tabel 1: Karateristik responden berdasarakan umur ibu hamil Trimester I di Wilayah Puskesmas Tiron Kecamatan Banyakan Kabupaten Kediri

\begin{tabular}{lccc} 
No & Usia (Tahun) & Frekuensi & Presentase $(\%)$ \\
\hline 1 & $<20$ tahun & 6 & 20 \\
\hline 2 & $20-35$ tahun & 22 & 73 \\
\hline 3 & $>35$ tahun & 2 & 7 \\
\hline & Jumlah & 30 & 100
\end{tabular}

Berdasarkan Tabel IV.1.1 didapatkan responden berumur $>35$ tahun yaitu sejumlah 2 bahwa dari 30 responden, Mayoritas responden responden (7\%). berumur 20-35 tahun yaitu sejumlah 22 responden $(73 \%)$ selanjutnya minoritas

Tabel.2: Karateristik responden berdasarkan Pendidikan ibu di Wilayah Puskesmas Tiron Kecamatan Banyakan Kabupatan Kediri

\begin{tabular}{cccc} 
No & Pendidikan & Frekuensi & Presentasi(\%) \\
\hline 1 & Tidak tamat SD & 1 & 3 \\
\hline 2 & SD/ Sederajat & 3 & 10 \\
\hline 3 & SMP/ Sederajat & 4 & 13 \\
\hline 4 & SMA / Sederajat & 20 & 67 \\
\hline 5 & Akademi/PerguruanTinggi & 2 & 7 \\
\hline & Jumlah & 30 & 100
\end{tabular}

Berdasarkan Tabel.2 didapatkan bahwa dari 30 responden (67\%) selanjutnya minoritas Tidak responden mayoritas responden adalah tamat SD yaitu sejumlah 1 responden (3\%). berpendidikan SMA/Sederajat yaitu sejumlah 20

Tabel IV.3: Karakteristik Responden Berdasarkan Pekerjaan Ibu Hamil Trimester I Di Wilayah Puskesmas Tiron Kecamatan Banyakan Kabupaten Kediri

\begin{tabular}{cccc} 
No & Pekerjaan & Frekuensi & Presentase $(\%)$ \\
\hline 1 & Ibu Rumah Tangga & 20 & 67 \\
\hline 2 & Petani & 3 & 10 \\
\hline 3 & PNS & 2 & 6 \\
\hline 4 & Swasta & 5 & 17 \\
\hline 5 & Wirausaha & 0 & 0 \\
\hline
\end{tabular}


Aida Ratna Wijayanti: Gambaran Pengetahuan Ibu Hamil Trimester I Tentang Hiperemesis Gravidarum (di Wilayah Puskesmas Tiron Kecamatan Banyakan Kabupaten Kediri)

\begin{tabular}{cccc}
\hline 6 & Lain-Lain & 0 & 0 \\
\hline & Jumlah & 30 & 100
\end{tabular}

Berdasarkan tabel IV.1.3 didapatkan (67\%) selanjutnya minoritas sebagai PNS yaitu dari 30 responden, mayoritas adalah sebagai Ibu sejumlah $\quad 2 \quad$ responden $\quad(6 \%)$ Rumah Tangga yaitu sejumlah 20 responden

Tabel IV.4: Karakteristik responden Berdasarkan pernah atau belum pernah mendapatkan informasi di Wilayah Puskesmas Tiron Kecamatan Banyakan Kabupaten Kediri

\begin{tabular}{cccc} 
No & Sumber Informasi & Frekuensi & Presentasi \\
\hline 1 & Pernah & 20 & 67 \\
\hline 2 & Tidak & 10 & 33 \\
\hline & Jumlah & 30 & 100
\end{tabular}

Berdasarkan tabel.4 didapatkan bahwa dari 30 responden, mayoritas pernah mendapat informasi tentang hiperemesis gravidarum yaitu sejumlah 20 responden $(67 \%)$ selanjutnya minoritas dimana responden tidak mendapatkan informasi tentang hipermesis gravidarum yaitu sejumlah 10 responden $(33 \%)$.

Tabel IV.5: Karateristik responden berdasarkan Sumber Informasi di Wilayah Puskesmas Tiron Kecamatan banykan Kabupaten Kediri

\begin{tabular}{cccc} 
No & Sumber Informasi & Frekuensi & Presentase(\%) \\
\hline 1 & Bidan / Nakes & 18 & 60 \\
\hline 2 & Media massa & 1 & 3 \\
\hline 3 & TV/ Elektronik & 1 & 3 \\
\hline 4 & Tidak Pernah & 10 & 34 \\
\hline & Jumlah & 30 & 100
\end{tabular}

Berdasarkan tabel 5 didapatkan bahwa dari 30 responden, mayoritas mendapat informasi dari Nakes/Bidan yaitu sejumlah 18 responden $(60 \%)$ selanjutnya minoritas dari

media massa dan Tv/Elektronik yaitu sejumlah 1 responden( $3 \%)$. Dan yang tidak mendapat informasi sejumlah 10 responden (34\%)

Tabel.6: Karateristik responden berdasarkan jumlah anak di Wilayah Puskesmas Tiron Kecamatan banykan Kabupaten Kediri

\begin{tabular}{cccc} 
No & Anak Ke & Frekuensi & Presentase $(\%)$ \\
\hline 1 & 1 & 5 & 16 \\
\hline 2 & 2 & 22 & 74 \\
\hline 3 & $>2$ & 3 & 10 \\
\hline & Jumlah & 30 & 100
\end{tabular}

Berdasarkan tabel.6 didapatkan bahwa dari 30 yang mempunyai anak $>2$ sejumlah 3 responden, mayoritas yaitu anak ke 2 sejumlah responden $(10 \%)$ 22 responden $(74 \%)$ dan minoritas yaitu ibu

Tabel.7: Distribusi frekuensi Ibu Hamil Trimester I berdasarkan Pengetahuan di Wilayah Puskesmas Tiron Kecamatan Banyakan Kabupaten Kediri.

\begin{tabular}{cccc} 
No & Pengetahuan & Frekuensi & Prosentase (\%) \\
\hline 1 & Baik & 3 & 10 \\
\hline 2 & Cukup & 17 & 57 \\
\hline 3 & Kurang & 10 & 33 \\
\hline & Total & 30 & 100
\end{tabular}


Berdasarkan tabel.7 dapat diketahui dari 30 responden mayoritas didapatkan 10 responden (33\%) berpengetahuan kurang, 17 responden
(57\%) berpengetahuan cukup, sedangkan

Tabel.8: Distribusi Frekuensi Gambaran Pengetahuan Ibu Hamil Trimester I tentang Hiperemesis Gravidarum di Wilayah Puskesmas tiron kecamatan Banyakan Kabupaten Kediri.

\begin{tabular}{cccccccccc}
\multirow{2}{*}{ No } & Kategori Hiperemesis & \multicolumn{2}{c}{ Baik } & \multicolumn{2}{c}{ Cukup } & \multicolumn{2}{c}{ Kurang } & \multirow{2}{*}{ Total } & \multirow{2}{*}{$\%$} \\
\cline { 3 - 9 } & Gravidarum & F & $\mathbf{\%}$ & F & $\mathbf{\%}$ & F & $\mathbf{\%}$ & & \\
\hline 1. & Pengertian & 13 & 43 & 9 & 30 & 8 & 27 & 30 & 100 \\
\hline 2. & Penyebab & 6 & 20 & 16 & 53 & 8 & 27 & 30 & 100 \\
\hline 3. & Diagnosis & 8 & 27 & 17 & 57 & 5 & 16 & 30 & 100 \\
\hline 4. & Pencegahan & 7 & 22 & 7 & 23 & 16 & 53 & 30 & 100
\end{tabular}

Berdasarkan tabel 8 menunjukan dari 30 Responden yang diteliti didapatkan: Pengetahuan ibu hamil tentang pengertian hiperemeis gravidarum sebanyak 13 responden (43\%) berpengetahuan baik. Pengetahuan ibu hamil tentang penyebab hiperemesis gravidarum sebanyak 16 responden (53\%) berpengetahuan cukup.

\section{Diskusi}

Hasil penelitian pada tabel.8 menunjukan bahwa pengetahuan responden tentang pengertian hipermesis gravidarum adalah baik $(43,3 \%)$ dan ada juga pengetahuan responden yang kurang $(26,6 \%)$.

Pendidikan berarti bimbingan yang diberikan seseorang terhadap perkembangan orang lain menuju kearah cita-cita tertentu untuk berbuat dan mengisi kehidupan, mencapai keselamatan dan kebahagiaan. Pendidikan diperlukan untuk mendapat informasi misalnya hal-hal yang menunjang kesehatan sehingga dapat meningkatkan kualitas hidup. Pendidikan dapat mempengaruhi seseorang termasuk juga perilaku seseorang akan pola hidup terutama dalam memotivasi untuk sikap berperan serta dalam pembangunan pada umumnya makin tinggi pendidikan seseorang makin mudah menerima informasi. (Wawan \& Dewi, 2010 : 16-17)

makin tinggi pendidikan seseorang, maka makin mudah menerima informasi sehingga makin banyak pula pengetahuan yang dimiliki. Responden yang berpendidikan tinggi akan
Pengetahuan ibu hamil tentang diagnosis hipermesis gravidarum sebanyak 17 responden (57\%) berpengetahuan cukup. Pengetahuan ibu hamil tentang pencegahan hiperemesis gravidarum sebanyak 16 responden (53\%) berpengetahuan mudah menyerap informasi, sehingga ilmu pengetahuan yang dimiliki lebih tinggi namun sebaliknya orang tua yang berpendidikan rendah akan mengalami hambatan dalan penyerapan informasi sehingga ilmu yang dimiliki juga lebih rendah yang berdampak pada kehidupannya.

Selain pendidikan, pekerjaan juga mempengaruhi pengetahuan. Berdasarkan tabel IV.3 dapat diketahui bahwa 30 responden , mayoritas 20 responden (67\%) adalah Ibu Rumah Tangga, sebanyak 2 responden $(6 \%)$ adalah PNS dan 3 responden (10\%) adalah Petani.

Pengetahuan ibu hamil juga dapat dipengaruhi oleh informasi dan sumber informasi. Hasil penelitian dari 30 responden dapat diketahui bahwa 30 responden, 20 responden $(67 \%)$ ibu hamil pernah mendapatkan informasi dan sebanyak 10 responden $(33,3 \%)$ ibu hamil belum pernah mendapatkan informasi. 20 responden $(60 \%)$ ibu hamil mendapatkan informasi dari Nakes/Bidan dan 1 responden (3\%) mendapatkan informasi dari media massa dan Tv/Elektronik. 
Maka dari itu responden atau khususnya ibu hamil trimester I harus aktif dalam mencari pengetahuan tentang hiperemesis gravidarum. Selain itu pihak ibu sendiri harus mempunyai kesadaran untuk mencari pengetahuan yang lebih banyak lagi tentang hiperemesis gravidarum. Ibu harus lebih banyak lagi mengikuti acara penyuluhan atau membaca buku agar informasi bertambah. Semakin banyak sumber informasi yang di gunakan maka pengetahuan seseorang akan semakin bertambah.

Kemampuan dalam penyerapan informasi ibu juga menunjang dalam memperoleh informasi. Ibu harus dapat menyerap informasi yang didapat manfaat bagi dirinya. Dengan itu maka informasi yang didapat tidak akan hilang begitu saja.

Hasil penelitian pada tabel IV.8 menunjukan bahwa pengetahuan tentang penyebab hiperemesis gravidarum adalah cukup $(53,3 \%)$ sedangkan yang berpengetahuan baik (20\%) dan yang berpengetahuan kurang sebesar $(23,3 \%)$.

Usia adalah umur individu yang terhitung mulai saat dilahirkan sampai berulang tahun. Semakin cukup umur, tingkat kematangan dan kekuatan seseorang akan lebih matang dalam berfikir dan bekerja. Dari segi kepercayaan masyarakat seseorang yang lebih dewasa dipercaya dari orang yang belum tinggi kedewasaanya. Hal ini akan sebagai dari pengalaman dan kematangan jiwa (Wawan \& Dewi, 2010 : 17).

Usia 20-35 tahun merupakan usia yang reproduktif bagi seseorang untuk dapat memotivasi diri memperoleh pengetahuan yang sebanyak-banyaknya. Umur individu yang terhitung mulai saat dilahirkan sampai saat berulang tahunJadi semakin matang usia seseorang, maka dalam memahami suatu masalah akan lebih mudah dan dapat menambah pengetahuan

Semakin banyak umur atau semakin tua seseorang maka akan mempunyai kesempatan dan waktu yang lebih lama dalam mendapatkan informasi dan pengetahuan. Dengan demikian semakin tua umur responden maka pengetahuanya ibu hamil hiperemesis gravidarum semakin baik.

Jika dikaitkan dengan umur maka responden yang hampir seluruhnya berumur 2035 tahun sebanyak 22 responden $(73,3 \%)$ maka kemampuannya dalam menerima informasi dapat diserap secara maksimal karena pada umur tersebut bisa dikatakan sudah dewasa. Akan tetapi pada penelitian ini didapatkan masih sebagian pengetahuannya cukup. Hal ini terjadi karena kurang aktifnya responden dalam mencari wawasan yang baru dalam kehidupannya.

Keaktifan responden sangat perlu ditingkatkan dengan cara mengikuti penyuluhan untuk mendapatkan informasi kesehatan. Selain itu motivasi dari petugas kesehatan sangat diperlukan untuk mendukung ibu dalam mendapatkan informasi yang mereka perlukan. Motivasi dari petugas kesehatan dapat dengan cara kunjugan rumah yang sekiranya dapat dilakukan pada ibu-ibu yang benar-benar membutuhkan motivasi dari petugas kesehatan. Misalnya ibu hamil yang tidak pernah datang ke petugas kesehatan untuk memeriksakan kehamilannya. Petugas kesehatan yang berada diwilayah tersebut seharusnya lebih memperhatikan masyarakat yang seperti itu agar mereka mendapatkan pelayanan konseling yang baik dan dapat mengetahui informasi dari petugas kesehatan.

Penyuluhan kesehatan dapat membantu unuk dijadikan sumber informasi yang mereka butuhkan. Apabila ibu memperoleh banyak pengetahuan maka dalam keadaan bagaimanapun ibu siap untuk mengahadapi dan tahu solusinya.

Hasil penelitian pada tabel IV.8 menunjukan bahwa pengetahuan responden tentang diagnosis hipermesis gravidarum adalah cukup (56,6\%). Dan sebagian masuk dalam kriteria kurang sebesar $(16,6 \%)$.

Menetapkan kejadian hiperemesis gravidarum tidak sukar, dengan menentukan kehamilan, muntah berlebihan sampai menimbulkan gangguan kehidupan sehari-hari dan dehidrasi. Muntah yang terus menerus tanpa pengobatan dapat menimbulkan gangguan tumbuh kembang janin dalam rahim dengan manifestas klinisnya. Oleh karena itu hiperemsis gravidarum berkelanjutan harus dicegah dan harus mendapat pengobatan yang adekuat. (Manuaba, 2010:229).

Informasi adalah sesuatu yang dapat diketahui, namun pula yang menekan informasi sebagai transfer pengetahuan. Selain itu informasi juga dapat didefinisikan sebagai suatu teknik untuk mengumpulkan, menyiapkan, menyimpan , memanipulasi , mengumumkan, menganalisis dan menyebarkan informasi dengan tujuan tertentu.(Budiman,2014:5) 
Dengan melihat hasil penelitian, peneliti berpendapat bahwa sebagian besar pengetahuan ibu tentang diagnosis hipermesis gravidarum adalah cukup. Oleh karena itu untuk meningkatkan pengetahuan responden adalah dengan cara memberikan penyuluhan tentang hipermesis gravidarum pada kehamilan. Karena perilaku yang didasari oleh pengetahuan akan lebih langgeng dari pada perilaku yang tidak didasari oleh pengetahuan. Maka dari itu pemberian pengetahuan tentang diagnosis hipermesis gravidarum sangat penting

Hasil penelitian dari 30 responden dapat diketahui bahwa 30 responden, 20 responden (67\%) ibu hamil pernah mendapatkan informasi dan sebanyak 10 responden $(33,3 \%)$ ibu hamil belum pernah mendapatkan informasi. 20 responden $(60 \%)$ ibu hamil mendapatkan informasi dari Nakes/Bidan dan 1 responden (3\%) mendapatkan informasi dari media massa dan Tv/Elektronik

Pengetahuan ibu tentang diagnosis hiperemesis gravidarum yang cukup diharapkan ibu dapat menerima gejala-gejala yang mungkin menyertai mual dan muntah pada awal kehamilan serta mencari informasi klinis dan diagnosis hiperemesis gravidarum.

Berdasarkan hasil penelitian pada tabel IV.8 menunjukan bahwa pengetahuan responden tentang pencegahan dari hipermesis gravidarum adalah kurang $(53,3 \%)$. dengan demikian masih ada $(23,3 \%)$ responden yang mempunyai pengetahuan baik dan cukup.

Pencegahan melalui Mengatur pola makan sedikit tapi sering. Waktu bangun pagi jangan segera turun dari tempat tidur, tetapi dianjurkan untuk makan roti kering atau biskuit dengan teh hangat. Makanan yang berminyak dan berbau lemak sebaiknya di hindarkan. Makanan dan minuman seyogyanya disajikan dalam keadaan panas atau sangat dingin. Defekasi yang teratur hendaknya dapat dijamin, menghindarkan kekurangan karbohidrat merupakan faktor yang penting, oleh karenanya dianjurkan makanan yang mengandung gula. (Yulianti, 2013:122).
Apabila dikaitkan dengan pekerjaan ibu berdasarkan tabel IV.3 dapat diketahui bahwa 30 responden , mayoritas 20 responden (67\%) adalah Ibu Rumah Tangga. Maka seharusnya dalam mendapatkan informasi ibu mempunyai banyak waktu dibandingkan ibu yang mempunyai pekerjaan diluar rumah. Dimana informasi dapat diperoleh dari media massa dan Tv/Elektronik. Selain itu ibu juga bisa mencari informasi melalui petugas kesehatan seperti mengikuti penyuluhan yang dilakukan tenaga kesehatan. Dari masyarakat juga bisa dijadikan sumber informasi. Mereka bisa saling bertukar pendapat mengenai informasi yang mereka peroleh khususnya mengenai kesehatan. Makan sedikit-sedikit tapi sering merupakan cara untuk mengurangi mual dan muntah(Anna,2007). Sebagian besar responden sudah mengetahui dan memahami bahwa cara untuk mencegah mual dan muntah adalah salah satunya dengan makan sedikit tapi sering, sehingga sesorang mengembangkan pengetahuan lebih dalam, mereka mau mencari informasi lebih banyak karena kebutuhan manusia dalam kehidupan tidak akan ada habisnya

\section{Simpulan}

Pencegahan terhadap hiperemesis gravidarum perlu dilaksanakan dengan jalan memberikan penerangan tentang kehamilan dan persalinan sebagai suatu proses yang fisiologik, terutama memberikan keyakinan bahwa mual dan kadang-kadang muntah merupakan gejala yang fisiologik pada kehamilan muda dan akan hilang setelah kehamilan bulan. Namun jika ini berlanjut mual dan muntah yang sering diikuti gejala Mual muntah berlebih yaitu lebih dari 10 kali dalam 24 jam disertai penurunan nafsu makan yang biasa disebut dengan Hiperemesis gravidarum. Keadaan seperti ini dapat mengganggu aktivitas ibu sehari-hari sehingga perlu diwaspadai dengan meningkatkan kewaspadaan secara dini melalui peningkatan pengetahuan tentang Hiperemesis Gravidarum. 
Aida Ratna Wijayanti: Gambaran Pengetahuan Ibu Hamil Trimester I Tentang Hiperemesis Gravidarum (di Wilayah Puskesmas Tiron

\section{Daftar Pustaka}

Almatsier, Sunita. 2010. Prinsip Dasar Ilmu Gizi. Jakarta : Gramedia Pustaka Utama

Ana,Soumy,2010. Trimester Pertama Kehamilan Anda.Jogjakarta: Buku Biru

Ariani, A.P. 2017. Ilmu Gizi. Yogyakarta : Nuha Medika

Ariani, Putri. 2014. Aplikasi Metodologi Penelitian Kebidanan dan Kesehatan Reproduksi. Yogyakarta: Nuha Medika

Departemen Gizi dan Kesehatan Masyarakat, 2014. Gizi Dan Kesehatan Masyarakat. Jakarta : Rajawali Pers

Djaeni, Dr. Achmad. 2008 . Ilmu Gizi. Jakarta : Dian Rakyat

Hasdianah , (ed), 2014. Gizi, Pemanfaatan gizi, Diet, dan Obesitas. Yogyakarta: Nuha Medika

Hidayat, Alimul Aziz, 2014. Metode Penelitian Kebidanan dan Teknik Analisis Data. Jakarta: Salemba Medika

2014. Metode Penelitian Kebidanan Dan Teknik Analisa data. Jakarta : Salemba Medika

Istiany, Ari. \& Rusilanti. 2014. Gizi Terapan. Bandung : Remaja Rosda

Kusmiran, Eny. Kesehatan Reproduksi Remaja Wanita. Jakarta : Salemba Medika

Kusmiyati,Yuni,2009.Perawatan

$\mathrm{Ibu}$ Hamil.Yogyakarta: Fitramaya

Laelatul, Dr Dewi. 2014. Gizi dalam Kesehatan Reproduksi. Bandung : Refika Aditama

Lia Yulianti,2013. Asuhan Kebidanan.Jakarta:Info Medika

Mansjoer,Arif,2008.Kapita Kedokteran.Jakarta: Media Aesculapius

Manuaba,C, A,2010. Ilmu Kebidanan Penyakit Kandungan dan KB.Jakarta:.EGC

Marmi, S.ST., M.Kes. 2014. Gizi dalam Kesehatan Reproduksi. Yogyakarta : Pustaka Pelajar

Notoadmodjo,S.2010.Metologi

Penelitian
2010. Metode Penelitian

Kesehatan. Jakarta: Rineka Cipta

2012. Metode Penelitian

Kesehatan. Jakarta : Rineka Cipta

Nursalam, 2014. Metode Penelitian Ilmu Keperawatan. Jakarta : Salemba Medika

.2013. Metodologi Penelitian Ilmu Keperawatan. Jakarta : Salemba Medika

.2011. Konsep dan Penerapan Metodologi Penelitian Ilmu Keperawatan: Pedoman Skripsi, Tesis dan Instrumen Penelitian. Jakarta: Saleba Medika 2011. Pedoman Skripsi, Tesis, dan nstrumen Penelitian Keperawatan . Jakarta: Salemba Medika

Poltekkes Depkes, 2009. Kesehatan Remaja. Jakarta : Salemba Medika

Proverawati K \& Kusumawati E. 2011. Ilmu Gizi Untuk Keperawatan Dan Gizi Kesehatan. Yogyakarta : Nuha Medika

Rusilanti,2014.Gizi Terapan.Bandung: Remaja Rosdakarya

Sarwono, Sarlito. 2013. Psikologi Remaja. Jakarta : Rajawali Pers

Supariasa,dkk. 2013. Penilaian Status Gizi. Jakarta: Buku Kedokteran EGC

Wawan \& Dewi. 2010. Pengetahuan, Sikap, dan Perilaku Manusia. Yogyakarta: Nuha Medika Pengetahuan Sikap Dan Perilaku Manusia. Yogyakarta: Nuha Medika 2015. Teori dan Pengukuran, Sikap dan Perilaku Manusia. Yogyakarta:Nuha Medika

Femmy. 2014. Faktor-faktor yang berhubungan denga kejadian hyperemesis gravidarum Available

From:http://download.portalgaruda.org/articl e.php? article $=402207 \&$ val $=6849 \&$ title $=$ [diakses pada 28 maret 2014] Kesehatan.Jakarta: Rineka Cipta 